\title{
Effect of Thiamine Status on Probability of Lake Ontario Chinook Salmon Spawning in the Upper or Lower Sections of Salmon River, New York
}

\author{
H. George Ketola* and James H. Johnson \\ U.S. Geological Survey, Great Lakes Science Center, Tunison Laboratory of Aquatic Science, \\ Cortland, New York 13045, USA \\ JACQUES RINCHARD ${ }^{1}$ \\ School of Natural Resources and Environment, University of Michigan, and U.S. Geological Survey, \\ Great Lakes Science Center, Ann Arbor, Michigan 48105, USA \\ Francis J. Verdoliva, Mary E. Penney, ${ }^{2}$ and Andreas W. Greulich \\ New York State Department of Environmental Conservation, \\ Salmon River Hatchery, Altmar, New York 13302, USA \\ Russell C. Lloyd \\ Cornell School of Hotel Administration, Cornell University, Ithaca, New York 14853, USA
}

\begin{abstract}
Consumption of thiaminase-containing forage fishes reduces egg and muscle thiamine content and impairs the spawning migration of Cayuga Lake (New York) rainbow trout Oncorhynchus mykiss. Because some Chinook salmon O. tshawytscha from Lake Ontario have been shown to produce eggs low in thiamine, we examined the relationship between the migration of Chinook salmon and the thiamine content of their eggs spawned in the lower and upper sections of the Salmon River, a major tributary to Lake Ontario, in 2003-2006. Eggs from the upper section of the river were collected from 79 salmon returning to the state hatchery 25 river kilometers from the mouth. Eggs from 25 salmon in the lower section were collected from redds or females angled on redds approximately $1-3 \mathrm{~km}$ from the mouth. For all years combined, we found the mean thiamine concentration in eggs spawned in the lower section to be significantly lower than that for eggs spawned in the upper section; however, the annual differences in thiamine content of eggs between the upper and lower sections were significant only in 2003 and 2006. Binary logistic regression showed that the odds of spawning in the upper section was increased by $96 \%$ (95\% confidence interval, 21-217\%) for every nanomole of increase in the thiamine content of eggs. Therefore, the migratory achievement of Chinook salmon was significantly dependent on their thiamine status.
\end{abstract}

Many spawning salmonines in several Great Lakes and Finger Lakes (New York) develop varying degrees of thiamine deficiency that is manifested in their fry as early mortality syndrome (EMS). Common clinical signs of EMS in fry include lethargy, loss of balance, exophthalmia, edema, hemorrhages, spiral or abnormal swimming, and eventual death (Ketola et al. 2000; Brown et al. 2005). Deficiency in adults is caused by high consumption of forage fishes such as alewives

\footnotetext{
* Corresponding author: gketola@usgs.gov

${ }^{1}$ Present address: Department of Environmental Science and Biology, The State University of New York College at Brockport, 350 New Campus Drive, Lennon Hall, Brockport, New York 14420, USA.

${ }^{2}$ Present address: New York Sea Grant Extension, Cornell University, State University of New York-Oswego, Oswego, New York 13126, USA.
}

Received October 9, 2007; accepted January 22, 2009 Published online June 18, 2009
Alosa pseudoharengus that contain high levels of thiaminase (Honeyfield et al. 2005; Tillitt et al. 2005), an enzyme that destroys thiamine (Neilands 1947). Thiaminase-induced thiamine deficiency has been reported for most Great Lakes salmonines, including Chinook salmon, coho salmon Oncorhynchus kisutch, lake trout Salvelinus namaycush, steelhead (anadromous rainbow trout) Oncorhynchus mykiss, brown trout Salmo trutta, and Atlantic salmon (Salmo salar) (Fitzsimons 1995; Marcquenski and Brown 1997; Brown et al. 1998; Hornung et al. 1998; Fitzsimons et al. 2001, 2005, 2007; Wolgamood et al. 2005; Werner et al. 2006).

Although much is known about the effects of thiamine deficiency in fry, relatively little is known about those in adults (Brown et al. 2005). Adult coho salmon migrating from Lake Michigan in the Platte River were shown to exhibit loss of equilibrium and wriggling behavior when severely thiamine deficient 
(Fitzsimons et al. 2005). Ketola et al. (2005) showed that thiamine-deficient adult rainbow trout had impaired ability to jump over barriers during their spawning migration upstream. Impaired ability to jump was statistically related to reduced concentrations of thiamine in their muscle. Ketola et al. (2005) also showed that the thiamine concentration in muscle was directly and significantly correlated $\left(r^{2}=0.85\right)$ to the concentration in eggs.

Chinook salmon in Lake Ontario have been shown to spawn eggs low in thiamine (Fitzsimons et al. 2007), yet no studies have been reported as to how thiamine status may impact their migration and location of spawning. Therefore, to assess thiamine status and migratory ability, we collected and analyzed eggs of Chinook salmon spawning from 2003 to 2006 in the upper and lower sections of the Salmon River, a large Lake Ontario tributary used by spawning salmon. Further, based on annual variations in egg thiamine content and a logistic regression relationship between egg thiamine concentration and EMS in Chinook salmon (Fitzsimons et al. 2007), we assessed the likelihood that Chinook salmon from Lake Ontario would spawn eggs whose fry would develop EMS as a result of thiamine deficiency.

\section{Methods}

Between 2003 and 2006, we collected eggs from Lake Ontario Chinook salmon spawning in the lower and upper sections of the Salmon River. The lower sampling site was approximately 1-3 river kilometers from the mouth of the river. The upper sampling site was the New York State Department of Environmental Conservation Salmon River Hatchery located at $75.99472^{\circ} \mathrm{W}$ longitude and $43.50923^{\circ} \mathrm{N}$ latitude (NAD83/WGS84 coordinate system), which is approximately 25 river kilometers from the mouth $\left(76.2029^{\circ} \mathrm{W}\right.$ and $\left.43.5752^{\circ} \mathrm{N}\right)$. The increase in elevation from the mouth was $0 \mathrm{~m}$ to the lower section and $93 \mathrm{~m}$ to the hatchery. Between the mouth and the hatchery, there are no dams, waterfalls, or barriers. The average percentage gradient (rise (m)/100-m run) from the mouth to the upper section is approximately $0.39 \%$.

Eggs.-Eggs from the upper section of the river were sampled between October 10 and 29. Eggs from the lower section were collected between October 29 and December 9 and either taken from redds (2003) or females angled on redds (2004-2006). In 2006, all eggs (both up- and downriver) were collected between October 16 and 18. A total of 104 samples of eggs were collected, 79 in the upper section and 25 in the lower section. Each year, between 5 and 7 samples were collected in the lower section and between 17 and 22 in the upper section.
Thiamine analyses.-Samples of eggs were immediately frozen by placing them in plastic bags and laying the bags directly on dry ice $\left(\leq-78.5^{\circ} \mathrm{C}\right)$ in an insulated chest at the river. Later that day the samples were transferred to a Revco ultrafreezer (Kendro Laboratory Products, Ashland, North Carolina), where they were held at $-80^{\circ} \mathrm{C}$ until analyzed. Eggs were analyzed for total thiamine $\left(T_{\mathrm{RM}}\right.$, i.e., the sum of free thiamine, thiamine monophosphate, and thiamine diphosphate) by the rapid method of Zajicek et al. (2005), who developed the method using salmonine eggs (including those of Chinook salmon). Those authors reported that the rapid method overestimated the concentration of thiamine relative to the values determined by the high-performance liquid chromatography $\left(T_{\text {HPLC }}\right)$ method of Brown et al. (1998). Zajicek et al. (2005) reported that the overestimation bias was linear and could be represented by the equation

$$
T_{\mathrm{RM}}=0.9641 \cdot T_{\mathrm{HPLC}}+1.6353 ; \quad r^{2}=0.94 .
$$

We report $T_{\mathrm{RM}}$ values obtained by the method of Zajicek et al. (2005) without adjustment. However, to compare our rapid-method values with the HPLC "threshold" egg thiamine values in the literature (i.e., the levels at which various degrees of mortality are observed), we used the above equation to convert the HPLC threshold values reported by Wolgamood et al. (2005) and Fitzsimons et al. (2007) (1.7 and $1.52 \mathrm{nmol} /$ $\mathrm{g}$ for $20 \%$ mortality [ED20]) to adjusted threshold values of 3.27 and $3.1 \mathrm{nmol} / \mathrm{g}$, respectively.

River flow rates.-Daily flow rates in the Salmon River (converted to cubic meters per second) for each lot of eggs on the day spawned and up to $7 \mathrm{~d}$ before were obtained from the U.S. Geological Survey Web site for the gauging station at Pineville (waterdata.usgs. gov).

Statistical analyses.-Because the egg thiamine data for years 2003 to 2005 and all years combined were neither normally distributed nor homoscedastic, we analyzed the differences between upriver and downriver using one-tailed Mann-Whitney tests (Zar 1999). Because the data for 2006 were normally distributed and had homogeneous variances, probability $(P)$ was analyzed by a one-tailed $t$-test for means with equal variances (Ott and Longnecker 2001). The annual egg thiamine concentrations for the downriver, upriver, and combined sections (by year) were not normally distributed; therefore, they were analyzed by the Kruskal-Wallis test (Ott and Longnecker 2001). The mean 7- and 4-d flow rate data for the samples collected up- versus downriver for years 2003 to 2006 were normally distributed and thus analyzed by paired $t$-tests. Because the upriver flow rates associated with 


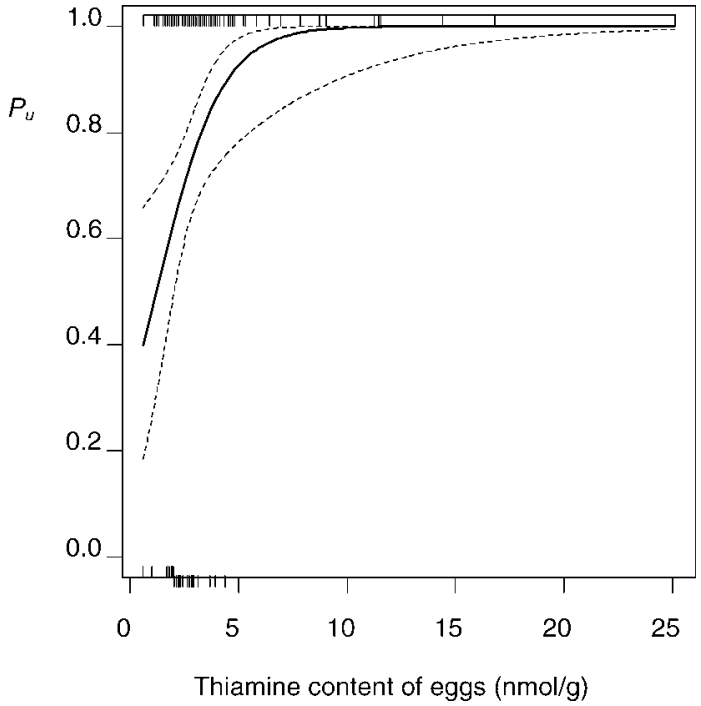

FIGURE 1.-Probability $\left(P_{u}\right)$ of Chinook salmon spawning in the upper section of the Salmon River in relation to the thiamine content of their eggs. The dashed lines indicate the 95\% confidence interval around the mean; the hatch marks show the thiamine contents of individuals spawning in the upper or lower section of the river.

each quartile of egg thiamine were not normally distributed, we analyzed them using one-tailed Mann-Whitney tests (Zar 1999). The Shapiro-Wilk test of normality, Bartlett's tests of homogeneity of variances, and the Kruskal-Wallis, Mann-Whitney, and $t$-tests were computed with Statistix for Windows 2003, version 8.0 (Analytical Software, Tallahassee, Florida). A probability level of less than 0.05 was considered significant.

To determine the relationship between spawning location and egg thiamine concentration, data for all years combined $(N=104)$ were analyzed by means of binary logistic regression (Agresti 2002) in Minitab version 14.1 (Minitab, State College, Pennsylvania). The significance of the regression was assessed via a one-tailed test, in which the null hypothesis (slope $\leq 0$ ) was rejected and the alternate hypothesis (slope $>0$ ) was accepted at $P=0.003$. The predicted mean probability $\left(P_{u}\right)$ that salmon would spawn in the upper section was computed as

$$
P_{u}=L /(L+1)
$$

where $L=e^{(0.6711 T-0.8155)}$.

This equation and its $95 \%$ confidence intervals was graphed (Figure 1) using the statistical program R (R Development Core Team 2007). The bias-normalized Akaike information criterion (Sugiura 1978) indicated that the model using untransformed thiamine concentrations gave a 4.5-times-better approximation to the true biological process of spawning site selection than $\log _{e}$ transformed concentrations (Burnham and Anderson 2002). Including flow rate data in our logistic regression model resulted in a failure of convergence due to insufficient sample size, thus prohibiting the evaluation of the influence of this variable.

\section{Results}

Table 1 shows that the combined mean (2003-2006) total thiamine content in Chinook salmon eggs collected in the upper section of the river was significantly greater $(P \leq 0.0005)$ than that of eggs collected in the lower section. The annual differences between the upper and lower sections were significant $(P \leq 0.009)$ in 2003 and 2006 but not in 2004 and 2005. For eggs from the upper and lower parts of the river combined, the thiamine content in 2003 was significantly higher than for eggs collected in 2006 but not for those collected in 2004 and 2005. The range of concentrations in all years for individuals spawning in the lower section of the river was $0.6-4.3 \mathrm{nmol} / \mathrm{g}$, whereas that for individuals spawning in the upper section was 0.6-25.1 nmol/g. During 2003-2005, nine fish $(12 \%)$ produced eggs having high concentrations of thiamine (between 7.8 and $25.1 \mathrm{nmol} / \mathrm{g}$ ), all of which spawned upriver (Figure 1). In contrast to previous years, eggs collected in the upper section in

TABLE 1.-Total thiamine content (nmol/g; mean \pm standard deviation) of Chinook salmon eggs spawned in different sections of the Salmon River from 2003 to 2006 . Within columns, values not followed by a common letter significantly differ $(P<0.01)$. The last column shows the probability of the differences (one-tailed tests) between the means for lower and upper sections being significant.

\begin{tabular}{llccl}
\hline & \multicolumn{3}{c}{ Section(s) } & \\
\cline { 2 - 4 } Year & Combined & Lower & Upper & \multicolumn{1}{c}{$P$} \\
\hline 2003 & $5.3 \pm 4.1(23) \mathrm{z}$ & $2.6 \pm 1.2(6) \mathrm{z}$ & $6.3 \pm 4.3(17) \mathrm{z}$ & 0.005 \\
2004 & $3.4 \pm 2.2(25) \mathrm{zy}$ & $2.6 \pm 0.4(5) \mathrm{z}$ & $3.6 \pm 2.4(20) \mathrm{y}$ & 0.4 \\
2005 & $4.3 \pm 4.7(27) \mathrm{zy}$ & $2.6 \pm 0.7(7) \mathrm{z}$ & $4.9 \pm 5.3(20) \mathrm{zy}$ & 0.14 \\
2006 & $2.5 \pm 0.8(29) \mathrm{y}$ & $1.9 \pm 0.7(7) \mathrm{z}$ & $2.7 \pm 0.7(22) \mathrm{y}$ & 0.009 \\
All & $3.8 \pm 3.4(104)$ & $2.4 \pm 0.8(25)$ & $4.3 \pm 3.7(79)$ & 0.0005 \\
\hline
\end{tabular}


TABLE 2.-Odds ratio (OR) and probability of spawning in the upper section of the Salmon River as predicted by thiamine concentration.

\begin{tabular}{lrrrrrrrr}
\hline & & & & & & \multicolumn{2}{c}{$95 \%$ confidence limits } \\
\cline { 7 - 8 } Parameter & Estimate & SE & $Z$ & $P$ & OR & Lower & Upper \\
\hline Constant & -0.8155 & 0.6809 & -1.20 & 0.231 & & & \\
Slope & 0.6711 & 0.2463 & 2.72 & 0.003 & 1.96 & 1.21 & 3.17 \\
\hline
\end{tabular}

2006 contained only low to modest levels of thiamine, ranging from 1.6 to $4.1 \mathrm{nmol} / \mathrm{g}$.

Using binary logistic regression (Table 2), we determined the odds ratio (OR) of salmon spawning upriver in relation to total thiamine concentration in their eggs. The odds $\left(O_{u}\right)$ of spawning upriver are related to the probability of spawning upriver by the equation

$$
O_{u}=P_{u} /\left(1-P_{u}\right) .
$$

The odds ratio (OR) equals the ratio of odds $\left(O_{u}\right)$ associated with thiamine concentrations differing by 1 unit $(\mathrm{nmol} / \mathrm{g})$. From the results of our analyses, we computed the odds ratio to be 1.96 ( $95 \%$ confidence interval, 1.21-3.17) and found its regression coefficient (slope $=0.6711)$ to be highly significantly different from zero (one-tailed $Z$-test; $P=0.003$ ). Therefore, the probability of spawning upstream significantly $(P=$ 0.003 ) increased with the thiamine concentration in eggs. Specifically, the estimated OR means that the odds of spawning in the upper section increased by $96 \%$ for every nanomole/gram of increase in the thiamine content of eggs. The equation for the probability of spawning in the upper section as a function of total thiamine concentration in eggs is

$$
P_{u}=\frac{e^{(0.6711 T-0.8155)}}{1+e^{(0.6711 T-0.8155)}} .
$$

From this equation, we estimated that the probability of spawning in the upper section was 0.95 and 0.80 for salmon with eggs containing 5.6 and $3.3 \mathrm{nmol} / \mathrm{g}$ thiamine, respectively. Figure 1 shows this relationship graphically.

Flow rates often varied greatly on a daily basis. The mean flow rate of the Salmon River during the periods of interest in our study was $23.1 \mathrm{~m}^{3} / \mathrm{s}$, but rates ranged from 11.1 to $57.2 \mathrm{~m}^{3} / \mathrm{s}$ owing to periodic releases of water from a utility company dam above the upriver site (data not shown). There was no significant difference $(P=0.54)$ between the mean flow rates encountered by salmon spawning up- and downriver (25.0 versus $20.1 \mathrm{~m}^{3} / \mathrm{s}$, respectively) during the $7 \mathrm{~d}$ prior to spawning; neither was there a significant difference $(P=0.65)$ during the $4 \mathrm{~d}$ prior to spawning
(26.5 versus $20.6 \mathrm{~m}^{3} / \mathrm{s}$, respectively; data not shown). When the upriver 7- and 4-d flow rates were sorted by their association with eggs having increasing concentrations of thiamine, we found that the flow rate for the lowest quartile of eggs was significantly lower than that for the highest quartile of eggs spawned upriver (Table 3).

\section{Discussion}

Binary logistic regression analyses showed that the migration distance of spawning Chinook salmon in the Salmon River increased significantly $(P=0.003)$ with thiamine status as indicated by the thiamine concentrations in their eggs (Table 2). These findings are in general agreement with those of Ketola et al. (2005), who showed that thiamine-deficient adult Cayuga Lake rainbow trout had reduced ability to jump over a $1.8-\mathrm{m}$ barrier during their spawning migration upstream. Although Chinook salmon encountered no barriers in the Salmon River, they had to endure a longer distance, migrating $25 \mathrm{~km}$ rather than the $8.7 \mathrm{~km}$ of trout from Cayuga Lake. Our results appear to differ from those of Fitzsimons et al. (2005), who found no effect of injecting thiamine into thiamine-deficient coho salmon

TABLE 3.- Mean flow rates $\left(\mathrm{m}^{3} / \mathrm{s}\right)$ for 7 or $4 \mathrm{~d}$ prior to Chinook salmon spawning in the upper section of the Salmon River and egg thiamine concentrations arranged by quartile. The last column shows the probability $(P)$ of differences between the mean flows associated with the first-, second-. or third-quartile thiamine concentrations and that of the highest (4th) quartile.

\begin{tabular}{ccccc}
\hline & \multicolumn{2}{c}{ Egg thiamine } & & \\
\cline { 2 - 3 } Quartile & Mean & Range & Mean flow & $P$ \\
\hline & & $\mathbf{7}$ days & & \\
1 & 1.8 & $0.6-2.4$ & 22.6 & 0.01 \\
2 & 2.8 & $2.4-3.2$ & 25.3 & 0.13 \\
3 & 3.8 & $3.3-4.3$ & 22.9 & 0.50 \\
4 & 8.9 & $4.5-25$ & 28.5 & \\
& & 4 days & & \\
1 & 1.8 & $0.6-2.4$ & 23.5 & 0.001 \\
2 & 2.8 & $2.4-3.2$ & 26.6 & 0.13 \\
3 & 3.8 & $3.3-4.3$ & 24.6 & 0.13 \\
4 & 8.9 & $4.5-25$ & 30.6 & \\
\hline
\end{tabular}


migrating from Lake Michigan up the Platte River a distance of $15 \mathrm{~km}$, where there were no obstacles and only a gentle gradient. The mean gradient in the Platte River was only $0.22 \%$ (determined from U.S. Geological Survey topographic maps), as compared with $0.39 \%$ in the Salmon River. However, the flow rates in the Salmon River during the 4- to 7-d intervals before each lot of eggs was spawned were much higher (range, 11.1-57.2 $\mathrm{m}^{3} / \mathrm{s}$ ) than those that the coho salmon encountered in the Platte River (range, 3.0-6.2 $\mathrm{m}^{3} / \mathrm{s}$; U.S. Geological Survey gauging station in Honor, Michigan) during the period of study (September 1130, 2001) by Fitzsimons et al. (2005). The low gradient, in combination with the low flow rate in the Platte River, probably explains why Fitzsimons et al. (2005) found no effect on the ability to migrate upstream from injecting thiamine into thiamine-deficient coho salmon, whereas we found a significant effect in Chinook salmon (this study) and rainbow trout (Ketola et al. 2005). Further, our data (Table 3) showed that upriver Chinook salmon that spawned eggs having thiamine concentrations in the lowest quartile encountered flow rates that were significantly lower $(P<0.01)$ than those encountered by salmon spawning eggs with thiamine concentrations in the highest quartile. This suggests that some Chinook salmon having a poor thiamine status (as reflected by the low concentrations of thiamine in their eggs) have been able to reach the upper section of the river by taking advantage of periods of reduced flow rates.

\section{Were the Results Confounded by Differences in the Time of Collection?}

The fact that many downriver salmon eggs were sampled later than those sampled upriver raises the possibility that downriver salmon consumed different types of forage just prior to spawning or experienced a longer period of nonfeeding that resulted in greater depletion of thiamine, stored energy (i.e., fat), or both. Therefore, while the apparent link between low thiamine content and impaired migration upriver seems to be real, it is possible that the results were confounded by differences in the depletion of stored energy, irrespective of thiamine. However, the data for 2006 showed that the mean concentration of thiamine in eggs collected upriver was significantly $(P<0.009)$ higher than in eggs collected downriver (Table 1) even though all 2006 samples were collected at practically the same time (between October 16 and 18). This observation suggests that the migration effects are related to thiamine and not simply a reflection of the differences in time of spawning or the depletion of body stores of energy.

It is widely recognized that thiamine deficiency causes general lethargy or weakness in fry, among other signs (Fisher et al. 1998; Ketola et al. 2000; Fitzsimons et al. 2005). Such lethargy or weakness in thiaminedeficient fry and migrating adults may be related to a reduced production of the high-energy metabolite adenosine triphosphate, which requires thiamine diphosphate for its production (Butterworth 1989).

Based on our observations with Chinook salmon and those with Cayuga Lake rainbow trout reported by Ketola et al. (2005), coupled with the widely recognized lethargy and weakness associated with thiamine deficiency, it is probable that thiamine deficiency impedes the migratory ability of other species of salmonines in other lakes where their forage includes a high proportion of thiaminase-containing forage fishes such as alewives. To determine how greatly thiamine deficiency impairs migration, further research is needed correlating the degree of thiamine deficiency in various species with their migration ability as related to gradient, flow rate, temperature, size, and the number of barriers encountered during the migration period.

\section{Calculation of Adjusted Critical Threshold Concentrations}

Wolgamood et al. (2005) estimated the total thiamine threshold of eggs of Chinook salmon from Lakes Michigan and Huron as $1.7 \mathrm{nmol} / \mathrm{g}$. Brown et al. (2005) reported that $0.6 \mathrm{nmol} / \mathrm{g}$ free (nonphosphorylated) thiamine in Lake Michigan Chinook salmon eggs (1998-1999) was associated with approximately $50 \%$ mortality from EMS. These authors did not report thresholds for total thiamine, nor did they report the relationship between free and total thiamine for the eggs in their studies. However, using a relationship (total thiamine $=1.1157 \cdot$ free thiamine $+0.3745 ; r^{2}=$ 0.98) that we derived from the data $(n=16)$ of Wolgamood et al. (2005), we calculated from the freethiamine value of Brown et al. (2005) that $1.04 \mathrm{nmol}$ total thiamine/g would be associated with $50 \%$ mortality. This calculated concentration is very close to the concentration of total thiamine $(1.03 \mathrm{nmol} / \mathrm{g})$ shown by Fitzsimons et al. (2007) to cause $50 \%$ mortality in Chinook salmon in Lake Ontario. To provide a more rigorous estimate of the egg threshold level for total thiamine, Fitzsimons et al. (2007) performed a logistic statistical analysis and computed the threshold resulting in $20 \%$ mortality (ED20) to be $1.52 \mathrm{nmol} / \mathrm{g}$ with a $95 \%$ confidence interval of 1.14 $2.01 \mathrm{nmol} / \mathrm{g}$, which encompasses the $1.7-\mathrm{nmol} / \mathrm{g}$ threshold of Wolgamood et al. (2005). These authors, however, analyzed thiamine by the HPLC method of Brown et al. (1998), which, as reported by Zajicek et al. (2005), results in statistically lower values than those determined by the rapid method used in our 
study. Accordingly, we adjusted the logistic value of Fitzsimon's ED20 threshold for total thiamine to obtain $3.10 \mathrm{nmol} / \mathrm{g}$ (95\% confidence interval, 2.73-3.57 $\mathrm{nmol} / \mathrm{g}$ ) using the equation of Zajicek et al. (2005). This adjustment for method of analysis does not assume that the HPLC method of Brown et al. (1998) is incorrect; on the contrary, it simply represents a practical attempt to compare results otherwise not possible owing to the disparity between the analytical results of the rapid and HPLC methods as reported by Zajicek at al. (2005).

Compared the observed concentrations of thiamine with the adjusted ED20 threshold (3.1 nmol/g) of Fitzsimons et al. (2007), we see that the mean concentrations of the eggs spawned in the lower part of the river were all below the adjusted threshold (Table 1) and therefore likely to produce fry that would die of EMS. In contrast, except for 2006, the mean concentrations of the eggs spawned in the upper part of the river all exceeded the threshold.

When the concentrations of thiamine in the eggs from individual fish that spawned in the upper section (data not shown) are compared with the adjusted threshold, all were adequate in thiamine 2003 and between $36 \%$ and $50 \%$ of the threshold from 2004 to 2006. In contrast, only $16 \%$ (4 out of 25 ) of all individual fish sampled in the lower section of the river (2003-2006) spawned eggs that were adequate in thiamine. In 2003, a maximum of $33 \%$ of the salmon (2 out of 6) in the lower section spawned eggs that contained sufficient thiamine to prevent EMS.

\section{Estimation of Thiamine-Adequate Eggs Spawned in the Lower Part of the Salmon River}

Although our results suggest high fry mortality due to EMS resulting from the low thiamine content of the eggs spawned in the lower sections of the river, the impacts on the population may actually be low. Everitt (2006) counted Chinook salmon redds in nine locations along the Salmon River (1,135 redds in total) during 2004 and 2005 from the lower section up to and including the hatchery and showed that only $9 \%$ of total redds were found in the lower section (our site). If only $9 \%$ of the Chinook salmon spawning in the river spawned at our downriver site, with our estimate that a mean of approximately 16\% (maximum, 33\% [2003]) of downriver salmon spawned eggs having thiamine concentrations sufficient to prevent EMS, we estimate that a mean of only $1.4 \%$ (maximum, $3 \%$ [2003]) of the Chinook salmon spawned eggs containing adequate thiamine in the lower section of the Salmon River. Therefore, it appears that only a trivial proportion of the salmon run deposited thiamine-adequate eggs downriver that may be subjected to possibly increased sedimentation and reduced intragravel oxygen related to downstream changes, as indicated by Chapman (1988) and Maret et al. (1993). Although such negative environmental impacts may be real, most likely there would be too small a proportion of thiamine-adequate salmon spawning in the lower section to have any appreciable effect on the Chinook salmon fishery in the Salmon River. This proportion might have been higher had the river offered greater challenges to migration (i.e., barriers, higher flow or gradient, etc.). A much greater effect may have been the loss of females that died before spawning that may have been the result of thiamine deficiency. Everitt (2006) estimated that between $55 \%$ and $60 \%$ the Chinook salmon in the river died before spawning and suggested that thiamine deficiency was a contributing factor. A study of the effects of hooking injuries by sportfishing in the Kenai River in Alaska suggests that hooking accounts for 7.6\% mortality (Bendock and Alexandersdottir 1993).

In conclusion, we found the four-year (2003-2006) mean thiamine concentration in Chinook salmon eggs spawned in the lower section of Salmon River to be significantly $(P<0.0005)$ lower than that of eggs spawned in the upper section. The concentrations of thiamine in eggs suggest that practically all of the Chinook salmon in the upper section spawned thiamine-adequate eggs in 2003, whereas 36-50\% spawned adequate eggs from 2004 to 2006. In contrast, only $16 \%$ of all individuals in the lower section of the river spawned eggs that were adequate in thiamine. Further, we found that the probability of spawning upriver increased significantly $(P<0.003)$ as thiamine status increased (as indicated by the concentration of thiamine in the eggs of Chinook salmon). It is probable that thiaminase-induced thiamine deficiency also impedes the upstream migration of other salmonines in the other four Great Lakes.

\section{Acknowledgments}

We thank Linda J. Begnoche of the Great Lakes Science Center for conducting analyses of thiamine and Phyllis L. Randall of the Tunison Laboratory, Aaron D. Switzer of the Michigan Department of Natural Resources, Platte River State Hatchery, Beulah, and Stephen P. Blumer of the U.S. Geological Survey, Lansing, Michigan, for technical assistance. We also thank Jean V. Adams of the Great Lakes Science Center for assistance with statistical analyses and graphics. This article is contribution 1518 of the Great Lakes Science Center.

\section{References}

Agresti, A. 2002. Categorical data analysis, 2nd edition. Wiley, Hoboken, New Jersey. 
Bendock, T., and M. Alexandersdottir. 1993. Hooking mortality of Chinook salmon released in the Kenai River, Alaska. North American. Journal of Fisheries Management 13:540-549.

Brown, S. B., M. T. Arts, L. R. Brown, M. Brown, K. Moore, M. Villella, J. D. Fitzsimons, B. Williston, D. C. Honeyfield, D. E. Tillitt, J. L. Zajicek, M. Wolgamood, and J. G. Hnath. 2005. Can diet-induced factors help explain fish-to-fish variation in thiamine and thiaminedependent early mortality syndrome? Journal of Aquatic Animal Health 17:36-47.

Brown, S. B., D. C. Honeyfield, and L. Vandenbyllaardt. 1998. Thiamine analyses in fish tissues. Pages 73-91 in G. McDonald, J. D. Fitzsimons, and D. C. Honeyfield, editors. Early life stage mortality syndrome in fished of the Great Lakes and Baltic Sea. American Fisheries Society, Symposium 21, Bethesda, Maryland.

Burnham, K. P., and D. R. Anderson. 2002. Model selection and multimodel inference, 2nd edition. Springer, New York.

Butterworth, R. F. 1989. Effects of thiamine deficiency on brain metabolism: implications for the pathogenesis of the Wernicke-Korsakoff syndrome. Alcohol and Alcoholism 24(4):271-279.

Chapman, D. W. 1988. Critical review of variables used to define effects of fines in redds of large salmonids. Transactions of the American Fisheries Society 117:121.

Everitt, D. W. 2006. Natural reproduction and spawning site characteristics of Chinook salmon (Oncorhynchus tshawytscha) in the Salmon River, New York. Master's thesis. State University of New York at Syracuse, Syracuse.

Fisher, J. P., S. B. Brown, S. Connelly, T. Chiotti, and C. C. Krueger. 1998. Interspecies comparisons of blood thiamine in salmonids from the Finger Lakes and effects of maternal size on blood and egg thiamine in Atlantic salmon with and without Cayuga syndrome. Pages 112-123 in G. McDonald, J. D. Fitzsimons, and D. C. Honeyfield, editors. Early life stage mortality syndrome in fished of the Great Lakes and Baltic Sea. American Fisheries Society, Symposium 21, Bethesda, Maryland.

Fitzsimons, J. D. 1995. The effect of B-vitamins on a swim-up syndrome in Lake Ontario lake trout. Journal of Great Lakes Research 21(Supplement 1):286-289.

Fitzsimons, J. D., H. G. Ketola, G. W. Wooster, and S. B. Brown. 2001. Use of thiamine antagonist to induce Cayuga-syndrome-like mortalities in larval Atlantic salmon. Journal of Aquatic Animal Health 13:151157.

Fitzsimons, J. D., B. Williston, P. Amcoff, L. Black, C. Pecor, H. G. Ketola, J. P. Hinterkopf, and D. C. Honeyfield. 2005. The effect of thiamine injection on upstream migration, survival, and thiamine status of putative thiamine-deficient coho salmon. Journal of Aquatic Animal Health 17:48-58.

Fitzsimons, J. D., B. Williston, P. G. Williston, L. Brown, A. El-Shaarawi, L. Vandenbyllaardt, D. C. Honeyfield, D. Tillitt, M. Wolgamood, and S. B. Brown. 2007. Egg thiamine status of Lake Ontario salmonines, 1995-2004, with emphasis on lake trout. Journal of Great Lakes Research 33:93-103.

Honeyfield, D. C., J. P. Hinterkopf, J. D. Fitzsimons, D. E. Tillitt, J. L. Zajicek, and S. B. Brown. 2005. Development of thiamine deficiencies and early mortality syndrome in lake trout by feeding experimental and feral fish diets containing thiaminase. Journal of Aquatic Animal Health 17:4-12.

Hornung, M. W., L. Miller, S. Marcquenski, and S. B. Brown. 1998. Efficacy of thiamine, astaxanthin, $\beta$ carotene, and thyroxine treatments in reducing early mortality syndrome on Lake Michigan salmonid embryos. Pages 124-134 in G. McDonald, J. D. Fitzsimons, and D. C. Honeyfield, editors. Early life stage mortality syndrome in fished of the Great Lakes and Baltic Sea. American Fisheries Society, Symposium 21, Bethesda, Maryland.

Ketola, H. G., P. R. Bowser, G. A. Wooster, L. R. Wedge, and S. S. Hurst. 2000. Effects of thiamine on reproduction of Atlantic salmon and a new hypothesis for their extirpation in Lake Ontario. Transactions of the American Fisheries Society 129:607-612.

Ketola, H. G., T. L. Chiotti, R. S. Rathman, J. D. Fitzsimons, D. C. Honeyfield, P. J. VanDusen, and G. E. Lewis. 2005. Thiamine status of Cayuga Lake rainbow trout and its influence on spawning migration. North American Journal of Fisheries Management 25:1281-1287.

Marcquenski, S. V., and S. B. Brown. 1997. Early mortality syndrome in salmonid fishes from the Great Lakes. Pages 135-152 in R. M. Rolland, M. Gilbertson, and R. E. Peterson, editors. Chemically induced alterations in functional development and reproduction of fishes. SETAC Press, Pensacola, Florida.

Maret, T. R., T. A. Burton, G. W. Harvey, and W. H. Clark. 1993. Field testing of new monitoring protocols to assess brown trout spawning habitat in an Idaho stream. North American Journal of Fisheries Management 13:567-580.

Neilands, J. B. 1947. Thiaminase in aquatic animals of Nova Scotia. Journal of the Fisheries Research Board of Canada 7:94-99.

Ott, R. L., and M. Longnecker. 2001. An introduction to statistical methods and data analysis, 5th edition. Duxbury Thomson Learning, Pacific Grove, California.

R Development Core Team. 2007. R: a language and environment for statistical computing, version 5.2.1. R Foundation for Statistical Computing, Vienna, Austria. Available: http://www.R-project.org. (August 2007).

Sugiura, N. 1978. Further analysis of the data by Akaike's information criterion and the finite corrections. Communications in Statistics: Theory and Methods 7(1):13-26.

Tillitt, D. E., J. L. Zajicek, S. B. Brown, L. R. Brown, J. D. Fitzsimons, D. C. Honeyfield, M. E. Holey, and G. M. Wright. 2005. Thiamine and thiaminase status in forage fish of salmonines from Lake Michigan. Journal of Aquatic Animal Health 17:13-25.

Werner, R. M., B. Rook, and R. Greil. 2006. Egg-thiamin status and occurrence of early mortality syndrome (EMS) in Atlantic salmon from the St. Marys River, Michigan. Journal of Great Lakes Research 32:293-305.

Wolgamood, M., J. G. Hnath, S. B. Brown, K. Moore, S. V. Marcquenski, J. P. Hinterkopf, and J. D. Fitzsimons. 
2005. Temporal and spatial variation of early mortality syndrome in salmonids from Lakes Michigan and Huron. Journal of Aquatic Animal Health 17:65-76.

Zar, H. J. 1999. Biostatistical analysis, 4th edition. PrenticeHall, Upper Saddle River, New Jersey.
Zajicek, J. L., D. E. Tillitt, S. B. Brown, L. R. Brown, D. C. Honeyfield, and J. D. Fitszimons. 2005. A rapid solidphase extraction fluorometric method for thiamine and riboflavin in salmonid eggs. Journal of Aquatic Animal Health 17:95-105. 